\title{
Nihil Novum Sub Sole
}

An Olympic year is always an opportunity to remember the past legendary feats that have seduced all of us to fall in love with sport. For a 41-year-old like myself, whose first contacts with sport and Olympics were in the ' 80 s, some memorable moments, such as the 100-m battle between Carl Lewis and Ben Johnson in the 1988 Summer Olympics, Seoul, South Korea, and the subsequent doping tragedy, are part of my childhood memories. All of us started in sport following our heroes and subsequently were introduced to a local training culture that involved the long-lasting heritage of sporting pioneers. During my sporting trip, I was very lucky to meet some coaches and professors who mentored ${ }^{1}$ me on the road trip to sport science. I would like to devote my first editorial to them because I realize, with my now 30 years of perspective, how important their life and sporting lessons were. One of the most important lessons has been that most concepts in sports physiology are really older than we all tend to think. That is the reason I decided to entitle this editorial "Nihil Novum Sub Sole" (nothing new under the sun), which is one of my favorite mottos learned during my high school Latin classes.

My track-and-field coach, Mr Manuel Rotea, was a pupil of Mr Luis Miró, who was the former Catalonian coach of Carlos Pérez, the first Olympian marathon runner from my city, Vigo. After our school team broke the regional record of $4 \times 60 \mathrm{~m}$, Mr Rotea invited me to train with him during the time he founded the first modern gym of our city. This was a very atypical circumstance because this meant that I trained more in the gym than on the track during my formative athletic years. He was often reading books and athletic journals, and always explained to us the rationale behind every coaching decision. This need of a defensible reason for every training step was definitively my main compass in all my future sporting interactions as an athlete, coach, and scientist.

My first memorable sports physiology lesson was during my first months in the gym. One day, Mr Rotea was trying to explain to a client that strength was not always related to hypertrophy. As an example, he asked me and Juan Luis, another 12-year-old sprinter, to push all the possible loads in the leg press machine (probably $>200 \mathrm{~kg}$ ). The surprise was not only for the client, but also for us, as we had never realized before that we were so strong. Thirty years later, it would seem that this is a novel idea given the recent discussion on the absence of contribution of muscle size on strength. ${ }^{2,3}$

Some time later, in the earlier 1990s, we were very lucky because Mr Rotea started the first course for coaches of the Spanish Olympic Committee. The teacher of strength training in that course was Professor Juan José González-Badillo, former coach of the Spanish national weightlifting team, who idealized the basis of velocity-based training (VBT) in the late 1970s. Because of this, we always trained following the VBT principles to avoid unnecessary fatigue during resistance training sessions. However, VBT was only introduced into the international scientific literature 30 years later. ${ }^{4}$ While VBT is now highly popular, not all colleagues know that this concept is not so novel.

Another important lesson for me was the use and application of the full "Bosco test," which I knew perfectly well before starting my undergraduate academic training. Mr Rotea had learned it from
Professor Rafael Martin-Acero, former coach of the Spanish national sprinting team, who learned it in the 1980s directly from the legendary Italian Professor, Carmelo Bosco. One of the evaluations of the "Bosco test" was to jump with different loads to identify if an athlete needed more emphasis on light or heavy loads in strength training. This pioneering work was the seed of the modern force-velocity profile subsequently introduced by Samozino et al. ${ }^{5}$

Some years later, Alexander Kudashov, an ex-Soviet athlete and track-and-field coach, arrived at Vigo. Alexander started to work as coach in the gym of Mr Rotea, who was sufficiently smart to know that this could be an extraordinary way to learn some Soviet sport science. For instance, on one occasion, Alexander showed me some algorithms to predict middle- and long-distance running performance, with an error $<3 \%$, which included some jumping evaluations, apart from the classic aerobic tests. This was before the first studies on the influence of neuromuscular factors on endurance running by Paavolainen et al. ${ }^{6,7}$ Another innovation I can remember was the use of the Nordic exercise for hamstrings injury prevention at a time in which no scientific literature existed on that topic. But the most epic moment with Alexander was monitoring postactivation potentiation and fatigue on the track with the use of a Soviet belt (with the sickle and the hammer in the buckle). The belt was linked to a measuring tape for recording the height of the Abalakov test performed before and between the running bouts. This experience inspired me, some years later, to look for postactivation potentiation in endurance runners in the field, first with a mat, ${ }^{8}$ and subsequently with a force plate. ${ }^{9}$

After remembering some of my past sporting experiences, I can only say that when we hear about the scientific importance of standing on the shoulders of giants, we should refer not only to pioneers in sports science, but also to those pioneer coaches and athletes who were always worried about learning and understanding the rationale behind their practices. I am sure that there is more old sport science in the field waiting to be rediscovered and published, some decades after a coach or an athlete had their first insights to improve performance.

All my respect to those sporting pioneers.

Daniel Boullosa, Associate Editor, IJSPP

\section{References}

1. Pyne D. The benefits of mentoring for researchers and sports scientists—who do I help? Int J Sports Physiol Perform. 2018;13(9): 1113. PubMed ID: 30314414 doi:10.1123/ijspp.2018-0688

2. Loenneke JP, Buckner SL, Dankel SJ, Abe T. Exercise-induced changes in muscle size do not contribute to exercise-induced changes in muscle strength. Sports Med. 2019;49(7):987-991. PubMed ID: 31020548 doi:10.1007/s40279-019-01106-9

3. Taber CB, Vigotsky A, Nuckols G, Haun CT. Exercise-induced myofibrillar hypertrophy is a contributory cause of gains in muscle strength. Sports Med. 2019;49(7):993-997. PubMed ID: 31016546 doi:10.1007/s40279-019-01107-8 
4. Sánchez-Medina L, González-Badillo JJ. Velocity loss as an indicator of neuromuscular fatigue during resistance training. Med Sci Sports Exerc. 2011;43(9):1725-1734. PubMed ID: 21311352 doi:10.1249/ MSS.0b013e318213f880

5. Samozino P, Rejc E, Di Prampero PE, Belli A, Morin JB. Optimal force-velocity profile in ballistic movements-altius: citius or fortius? Med Sci Sports Exerc. 2012;44(2):313-322. PubMed ID: 21775909 doi:10.1249/MSS.0b013e31822d757a

6. Paavolainen LM, Nummela AT, Rusko HK. Neuromuscular characteristics and muscle power as determinants of 5-km running performance. Med Sci Sports Exerc. 1999;31(1):124-130. PubMed ID: 9927020 doi:10.1097/00005768-199901000-00020
7. Paavolainen L, Häkkinen K, Hämäläinen I, Nummela A, Rusko H. Explosive-strength training improves $5-\mathrm{km}$ running time by improving running economy and muscle power. $J$ Appl Physiol. 1999;86(5):1527-1533. PubMed ID: 10233114 doi:10.1152/jappl. 1999.86.5.1527

8. Boullosa DA, Tuimil JL. Postactivation potentiation in distance runners after two different field running protocols. J Strength Cond Res. 2009;23(5):1560-1565. PubMed ID: 19620906 doi:10. 1519/JSC.0b013e3181a3ce61

9. Boullosa DA, Tuimil JL, Alegre LM, Iglesias E, Lusquiños F. Concurrent fatigue and potentiation in endurance athletes. Int J Sports Physiol Perform. 2011;6(1):82-93. PubMed ID: 21487152 